\title{
EL DERECHO AL MEDIO AMBIENTE SANO COMO UN DERECHO AUTÓNOMO EN EL SISTEMA INTERAMERICANO DE DERECHOS HUMANOS*
}

\author{
Digno José Montalván Zambrano** \\ Universidad Carlos III de Madrid
}

\section{RESUMEN}

La Opinión Consultiva de la Corte Interamericana de Derechos Humanos N. ${ }^{\circ}$ OC-23/17, de 15 de noviembre de 2017, sobre medio ambiente y derechos humanos y la sentencia del caso Lhaka Honhat vs. Argentina, de 6 de febrero de 2020, desarrollan el contenido del derecho al medio ambiente sano desde un enfoque que podríamos advertir como ecocéntrico. Este derecho, como derecho autónomo, protege a la naturaleza ya no solo por su utilidad para el ser humano (visión antropocéntrica-instrumental), sino por su importancia para los demás organismos vivos con quienes se comparte el planeta (visión ecocéntrica-no instrumental). El presente trabajo analiza este nuevo derecho dando cuenta tanto de los posibles presupuestos filosóficos jurídicos que lo informan como de los posibles cambios que este nuevo enfoque puede traer en el Sistema Interamericano de Derechos Humanos.

PALABRAS ClAVE: derecho al medio ambiente sano, derechos de la naturaleza, ecocentrismo, antropocentrismo, Corte Interamericana de Derechos Humanos.

\section{THE RIGHT TO A HEALTHY ENVIRONMENT AS AN AUTONOMOUS RIGHT IN THE INTER-AMERICAN HUMAN RIGHTS SYSTEM}

\section{Abstract}

The Advisory Opinion of the Inter-American Court of Human Rights No. OC-23/17, of 15 November 2017, on "Environment and Human Rights" and the ruling in the case Lhaka Honhat V. Argentina of 6 February 2020, develops the content of the right to a healthy environment from an approach that we could see as ecocentric. This right, as an autonomous right, protects nature not only because of its usefulness for human beings (anthropocentric-instrumental vision), but also because of its importance for other living organisms with which the planet is shared (biocentric-not instrumental vision). This paper analyzes this new right, giving an account of the possible legal philosophical presuppositions that inform it, as well as the possible changes that this new approach may bring to the Inter-American System of Human Rights.

KEYwORDs: right to a healthy environment, rights of nature, ecocentrism, anthropocentrism, Inter-American Court of Human Rights. 


\section{A MODO DE INTRODUCCIÓN: DE LA INTENSIFICACIÓN \\ DE LA MINERÍA A LOS DERECHOS DE LA NATURALEZA, LA EVOLUCIÓN DE LA CUESTIÓN AMBIENTAL EN LA NORMATIVA Y JURISPRUDENCIA INTERAMERICANA}

El 30 de abril de 1948 se aprobó el texto original de la Carta de la Organización de Estados Americanos (en adelante, Carta de la OEA), en cuyo artículo 26 los Estados se comprometían a cooperar entre sí a fin de, entre otros, «intensificar su agricultura y su minería». 19 años más tarde, el 27 de febrero de 1967, el «Protocolo de Buenos Aires» reformó dicho artículo 26, eliminando el objetivo de «intensificación de la minería» e incluyendo el "desarrollo integral» como nueva meta y concepto dentro de la Carta ${ }^{1}$. En esta primera etapa el desarrollo integral proponía un modelo basado en la expansión del uso de la tierra e industrialización acelerada que, con rasgos sociales, pero no ecológicos, buscaba lo que la misma Carta define como "desarrollo sostenido» (actual art. 34 de la Carta).

En noviembre de 1969 se suscribe la Convención Americana sobre Derechos Humanos y en esta tampoco se contempla ninguna disposición relativa al medio ambiente. Tendrían que pasar 19 años, esto es, hasta la aprobación en 1988 del Protocolo Adicional a la Convención Americana sobre Derechos Humanos en materia de derechos económicos, sociales y culturales (Protocolo de San Salvador), para que la preocupación por el medio ambiente aparezca en la normativa interamericana de la mano del derecho humano a un medio ambiente sano (artículo 11 del Protocolo).

Cuatro años más tarde, en 1992, se aprueba en Rio de Janeiro la Declaración de Naciones Unidas sobre Medio Ambiente y el Desarrollo y, con ella, se introduce el concepto de "desarrollo sostenible» en la normativa universal. Con este antecedente, en 1993 se reforma Carta de la OEA y se crea el Consejo Interamericano para el Desarrollo Integral (CEDI) (artículos 93 a 98 de la Carta), al cual se le otorga la responsabilidad de promover y coordinar el desarrollo de programas relativos a, entre otros, el «desarrollo económico y social, incluyendo [...] el medio ambiente» (art. 95).

Tres años después, el 8 de diciembre de 1996, los jefes de Estado y de Gobierno de las Américas aprueban la Declaración de Principios sobre Desarrollo Sostenible y, seis meses más tarde, el 5 de junio de 1997, la Asamblea General de

* La realización de este trabajo ha tenido lugar en el marco del proyecto de investigación "Jueces en Democracia. La filosofía política de la Corte Interamericana de Derechos Humanos» (DER2016- 79805-P, AEI/FEDER, UE) y del proyecto «Teorías de la justicia y derecho global de los derechos humanos» (PID2019 107172RB-I00), ambos financiados por el Ministerio de Ciencia e Innovación de España y adscritos al Grupo de Investigación sobre el Derecho y la Justicia de la UC3M.

** Investigador predoctoral (FPI-MINECO) y miembro del grupo de investigación sobre el derecho y la justicia (GIDyJ) de la Universidad Carlos III de Madrid. Trabajó como abogado especialista en derechos sociales de la dirección nacional de la Defensoría del Pueblo de Ecuador; actualmente es cocoordinador del taller sobre el derecho y la justicia de la Universidad Carlos III de Madrid y editor de Eunomia, Revista en cultura de la legalidad.

${ }^{1}$ Actuales artículos 30 al 52 de la Carta de la OEA. 
la OEA aprueba el Plan Estratégico de Cooperación Solidaria 1997-2001, el cual contemplaba como uno de sus objetivos la conservación del medio ambiente y el «desarrollo sostenible». Con ello, casi cincuenta años después de la aprobación de la Carta de la OEA, se supera el modelo extractivo de "desarrollo sostenido" y se da paso al modelo de "desarrollo sostenible». Este se consolida con la aprobación de la Carta Democrática Interamericana el 11 de septiembre de 2001, en cuyo artículo 15 se establece la obligación de implementar "políticas y estrategias de protección del medio ambiente [...] para lograr un "desarrollo sostenible" en beneficio de las futuras generaciones». Producto de lo anterior, el "desarrollo integral» deja su inicial vocación extractiva vinculada al enfoque del «desarrollo sostenido» y pasa a ser definido dentro del sistema interamericano como «el nombre general dado a una serie de políticas que trabajan conjuntamente para fomentar el desarrollo sostenible» ${ }^{2}$.

Este cambio tendría un gran impacto en el sistema interamericano de protección de derechos humanos. Así, ese mismo año, el 31 de agosto de 2001, la Corte Interamericana de Derechos Humanos (en adelante, Corte IDH) emite la sentencia del caso de la Comunidad Mayagna (Sumo) Awas Tingni vs. Nicaragua, la primera en referirse a la relación ser humano-naturaleza en el marco de los derechos humanos ${ }^{3}$. Desde ese momento, la Corte comienza a desarrollar una prolífera jurisprudencia sobre la importancia de la protección del ambiente para la realización de los derechos humanos, haciendo uso, durante 16 años, de la protección por conexión ${ }^{4}$. Esto es, sin declarar directamente vulnerado el derecho al ambiente sano consagrado en el artículo 11 del Protocolo de San Salvador, sino dando cuenta de cómo las afectaciones ambientales creaban escenarios de vulneración de derechos civiles y políticos. Bajo esta forma de protección, siguiendo la propuesta del «desarrollo sostenible», la naturaleza importa únicamente en tanto que instrumento indispensable para la vida humana, es decir, no se protege a la naturaleza toda, sino únicamente a aquellos aspectos ambientales esenciales para el cumplimiento de los derechos humanos.

Finalmente, el 15 de noviembre de 2017, en la Opinión Consultiva 23/17 sobre medio ambiente y derechos humanos (en adelante OC 23/17), la Corte IDH da un giro respecto de la protección por conexión e instrumental antes expuesta y

2 Así define actualmente desarrollo integral la Secretaría Ejecutiva para el Desarrollo Integral de la OEA (SEDI). Al respecto véase http://www.oas.org/es/temas/desarrollo_integral.asp (fecha de última consulta: 17/09/2020).

${ }^{3}$ Corte Interamericana de Derechos Humanos, Sentencia del caso de la Comunidad Mayagna (Sumo) Awas Tingni vs. Nicaragua de 31 de agosto de 2001, párr. 149.

${ }^{4}$ Casos: Comunidad indígena Yakye Axa vs. Paraguay, 2005, párr. 163; caso del Pueblo Saramaka vs. Surinam, 2007, párr. 126; caso Kawas Fernández vs. Honduras, 2009, párr. 148; caso de la comunidad indígena Xákmok Kásek vs. Paraguay, 2010, párr. 169-170; caso Pueblo Indígena Kichwa de Sarayaku vs. Ecuador, 2012, párr. 147; caso de las comunidades afrodescendientes desplazadas de la Cuenca del Río Cacarica (Operación Génesis) vs. Colombia, 2013, párr. 354; caso comunidad Garífuna de punta piedra y sus miembros vs. Honduras, 2015, párr. 125-129; caso pueblos Kaliña y Lokono vs. Surinam, 2015, párr. 181. 
consagra lo que denomina «el derecho al medio ambiente sano como derecho autónomo». Este nuevo derecho, tal como lo expone la misma Corte, "protege los componentes del medio ambiente, tales como bosques, ríos, mares y otros, como intereses jurídicos en sí mismos, aún en ausencia de certeza o evidencia sobre el riesgo a las personas individuales" ${ }^{5}$.

Más de dos años después, en su más reciente sentencia en la materia, el caso comunidades indígenas miembros de la Asociación Lhaka Honhat (nuestra tierra) vs. Argentina, de 6 de febrero de 2020, la Corte declara, por primera vez en un caso contencioso, la vulneración del derecho al medio ambiente sano como derecho autónomo, reiterando que dicho derecho «trata de proteger la naturaleza», no solo por su «utilidad» o «efectos» respecto de los seres humanos, «sino por su importancia para los demás organismos vivos con quienes se comparte el planeta ${ }^{6}$. De esta forma, el interés por la preservación de la naturaleza ya no gira exclusivamente en torno al ser humano, sino, también, a la naturaleza misma. Surge así una mirada «ecocéntrica» de la relación humano-naturaleza dentro del sistema interamericano de derechos humanos, la cual, tal como ha sido incorporada dentro del discurso jurídico, desemboca en la idea de los «derechos de la naturaleza».

Siguiendo esta línea evolutiva, el presente artículo presenta las razones que nos permiten afirmar que "el derecho al medio ambiente sano como derecho autónomo" se separa de la tradicional vertiente antropocéntrica bajo la cual se ha construido el discurso del derecho al "ambiente sano». Con este objetivo, en primer lugar, se efectúa una breve aproximación sobre las discusiones filosófico-políticas que, en nuestra consideración, inspiraron e inspiran las apuestas por el derecho al desarrollo (en su primera formulación de desarrollo sostenido no ambientalmente comprometido), el derecho al medio ambiente (vinculado a la idea antropocéntrica de desarrollo sostenible) o los derechos de la naturaleza (de matriz ecocéntrica); en segundo lugar, se explica el contenido que ha dado la jurisprudencia interamericana a la tradicional versión antropocéntrica del derecho a un medio ambiente sano; en tercer lugar, se presenta el contenido de la vertiente que denominamos ecocéntrica y cercana a los derechos de la naturaleza, esto es, del derecho a un medio ambiente sano como derecho autónomo, y, finalmente, se ofrecen conclusiones respecto de las oportunidades y desafíos de esta nueva visión.

5 Corte Interamericana de Derechos Humanos, Opinión Consultiva OC-23/17, medio ambiente y derechos humanos, de 15 de noviembre de 2017, párr. 62.

${ }^{6}$ Corte Interamericana de Derechos Humanos, Sentencia del caso comunidades indígenas miembros de la Asociación Lhaka Honhat (nuestra tierra) vs. Argentina, de 6 de febrero de 2020, párr. 203. 


\section{ANTROPOCENTRISMO Y ECOCENTRISMO: UNA APROXIMACIÓN CONCEPTUAL ${ }^{7}$}

La evolución normativa y jurisprudencial expuesta en el apartado anterior puede ser explicada a partir de su puesta en común con las distintas posturas filosóficas que han guiado nuestros debates sobre la relación humano-naturaleza. Vista de esta forma, dicha evolución sería prueba del largo camino recorrido desde que el Cogito cartesiano, base del racionalismo occidental, consagrara el imperio de la razón sobre la materia y, con ello, la división humano-naturaleza ${ }^{8}$. De esta división surgió una visión mecanicista de la vida física que, en términos morales, desembocó en lo que el juez de la Corte IDH Eugenio Raúl Zaffaroni llama el "despropósito de René Descartes»", esto es, la concepción de los animales como máquinas ${ }^{10}$, como simples cosas desposeídas de toda alma sobre las que no existe obligación alguna.

El tipo de relacionalidad cartesiana forjó el sistema de valores que está en la base de nuestra cultura ${ }^{11}$, una doctrina en la que el ser humano es el "centro» $y$ único destinatario de las preocupaciones morales, mientras que la naturaleza, en su consideración de "cosa», importa únicamente de manera indirecta, es decir, en tanto que recurso necesario para nutrir nuestros procesos productivos e idea de desarrollo. La propuesta del «desarrollo sostenido» que dominó la primera etapa de la normativa interamericana responde a esta aproximación, esto es, un modelo de desarrollo sin ninguna preocupación ambiental.

El carácter insostenible de esta aproximación generó en la filosofía y, más adelante, en el derecho respuestas diversas sobre nuestro entendimiento y relación con la naturaleza. Estas respuestas, a grandes rasgos, se pueden clasificar en tres grupos: 1) las respuestas antropocéntricas de inspiración kantiana sobre los deberes indirectos hacia la naturaleza. De estas se desprenden los enfoques normativos «ambientalistas» que, en el derecho, han tomado el nombre de «derecho al ambiente sano»; 2) las respuestas biocéntricas inspiradas en el utilitarismo de Jeremy Bentham, que, en el derecho, han dado forma a la corriente de los derechos de los animales, y 3 ) las respuestas ecocéntricas formuladas en Occidente desde el ecologismo profundo (Deep ecology) -cuyas raíces se han rastreado hasta la idea de autorrealización de Spino-

7 No es el objetivo de este trabajo abordar a profundidad el debate teórico sobre estos dos conceptos. Para un estudio más detallado de los términos antropocentrismo, biocentrismo, ecocentrismo y sus traducciones legales, se puede consultar Montalván Zambrano, D., "Justicia ecológica = Ecological justice», Eunomí. . Revista en Cultura de la Legalidad, 18, 2020, pp. 179-198. https:// doi.org/10.20318/eunomia.2020.5272.

${ }^{8}$ Capra, F., El punto crucial, Editorial Troquel, Buenos Aires, 1992, p. 30.

9 Zaffaroni, E., La Pachamama y el humano, Ediciones Madres de Plaza de Mayo, Ciudad Autónoma de Buenos Aires, 2011, pp. 34-35.

${ }^{10}$ Descartes, R., Discurso del método; Meditaciones metafísicas, Tecnos, Madrid, 2002 [1637], p. 114.

${ }^{11}$ Capra, F., El punto crucial, Editorial Troquel, Buenos Aires, 1992, p. 27 y ss. 
za- ${ }^{12}$, pero que, además, han emergido de la revitalización de otras aproximaciones sobre el Ser históricamente relegadas, tales como el $a t m a n^{13}$ del pensamiento oriental o la ética de la Pachamama (madre tierra) del pensamiento andino ${ }^{14}$. Estas respuestas ecocéntricas han dado paso a una nueva corriente en el campo jurídico, los derechos de la naturaleza.

La segunda de estas respuestas, esta es, la corriente biocéntrica de los derechos de los animales, aunque plausible como propuesta normativa independiente, es, en nuestra opinión, incompatible con el discurso de los derechos humanos. Dado que el locus central de los derechos humanos es, inevitablemente, el ser humano, las dos únicas formas de incorporar al ambiente dentro de este discurso, en nuestra consideración, serían 1) plantear una redefinición de «lo humano», esto es, de aquello que nos constituye y que, por tanto, dentro de los derechos humanos debe ser protegido, o 2) dar cuenta de por qué es importante para el cumplimiento de los fines humanos preservar ciertos elementos ambientales.

El discurso de los derechos de los animales prescinde por completo de los dos objetivos antes expuestos. Así, no pretende dar cuenta de que el mundo no humano es parte constitutiva del ser humano ni de que le es funcionalmente relevante; por el contrario, desarrolla su argumentación en la vertiente inversa, esto es, «humanizando» a los animales. Pretende dar cuenta de que la separación de los animales sensibles de la comunidad moral es un prejuicio irracional basado en el «especismo»" ${ }^{15}$. Peter Singer, uno de los autores más relevantes de esta corriente, siguiendo la propuesta utilitarista de Jeremy Bentham ${ }^{16}$, considera que dicho especismo estaría en excluir del círculo moral a otras especies que, «al igual que nosotros», poseen la capacidad de sentir. El «nosotros antropocéntrico» es el parámetro de referencia, por lo que la menor o mayor relevancia moral de esas otras especies será directamente proporcional a su similitud con el ser humano. En esta misma línea, más recientemente, Martha Nussbaum ha ofrecido argumentos a favor de los derechos de los animales desde su propuesta del enfoque de las capacidades ${ }^{17}$, que,

12 DE Jonge, E., Spinoza and Deep Ecology. Challenging Traditional Approaches to Environmentalism, Routledge, Abingdon, 2004.

13 DE Jonge, E., op. cit, 2004, pp. 37-40.

${ }_{14}$ Zaffaroni, E., op. cit, 2011, pp. 117-123.

15 Singer, P., Liberación animal, Trotta, Madrid, 1999, p. 42.

${ }^{16}$ Este autor, con su búsqueda de la mayor felicidad para todos y, por tanto, inclinado a evitar el dolor en los seres sensibles, reconoció que los animales, "seres sensibles que han sido degradados a la clase de cosas por la insensibilidad de los antiguos juristas», son, en realidad, merecedores de respeto y del reconocimiento de sus derechos: Bentham, J., Introduction to the Principles of Morals and Legislation, The Clarendon Press, Oxford, 1879, p. 310. Traducción propia.

${ }_{17} \mathrm{Al}$ respecto, la autora establece: «Al permitir reconocer una amplia variedad de tipos de dignidad animal (y de las correspondientes necesidades para su florecimiento), y al dedicar atención a la diversidad de actividades y de objetivos de criaturas de múltiples clases, el mencionado enfoque es capaz de producir normas de justicia "interespecies" que, aun siendo sutiles, resultan a la vez exigentes e implican derechos fundamentales para criaturas diversas». Nussbaum, M., Las fronteras de la justicia: Consideraciones sobre la exclusión, Paidós, España, 2007, p. 323. 
con una jerarquía de especies fundamentada en el sensocentrismo, parece caer en el mismo argumento utilitarista ${ }^{18}$.

De este modo, al perseguir el discurso de los derechos de los animales un telos distinto al de los derechos humanos, y al no existir en el marco biocéntrico una propuesta dirigida a unir o establecer conexiones (más allá de analogías antropocéntricas) entre el mundo humano y el mundo animal, consideramos que no hay intervención posible de este enfoque dentro del marco de los derechos humanos. Así lo ha demostrado, por ejemplo, la Corte Europea de Derechos Humanos, al entender que el bienestar animal no es, en sí mismo, un bien a proteger dentro de los derechos humanos ${ }^{19}$.

Aclarado lo anterior, pasaré ahora a referirme a las dos respuestas que, en nuestra consideración, sí pueden ser trasladadas al discurso de los derechos humanos: las antropocéntricas y las ecocéntricas. En primer lugar, el antropocentrismo es la doctrina por la cual el ser humano es la sede y medida de todo valor ${ }^{20} \mathrm{o}$, más concretamente, «el error de dar una consideración exclusiva o arbitrariamente preferente a los intereses humanos frente a los intereses de otros seres ${ }^{21}$. Así, en su modelo perfecto, el antropocentrismo «otorga todos los derechos al hombre y ninguno a la naturaleza $»^{22}$. Es uno de los fundamentos más importantes de la idea moderna de derechos humanos y, con ello, un punto de partida insoslayable, incluso cuando hablamos del derecho humano al medio ambiente sano ${ }^{23}$, cuyo origen podemos rastrear, precisamente, hasta el antropocentrismo kantiano.

Para Kant, la razón, es decir, la capacidad del ser humano para proponerse fines a su arbitrio, es aquello que le hace merecedor de un fin en sí mismo y, por ende, de dignidad. De estas características desprende una conclusión fundamental dentro de sus reflexiones teleológicas sobre la relación ser humano-naturaleza: el posicionamiento del ser humano como el fin último del reino de los fines o, en sus palabras, «el fin en relación al cual todas las demás cosas de la naturaleza constituyen un sistema de fines ${ }^{24}$. El planteamiento ético que surge de lo anterior es la

${ }_{18}$ Nussbaum, M., op. cit, p. 347.

19 Al respecto se puede consultar Sparks, T., «Protection of Animals Through Human Rights: The Case-Law of the European Court of Human Rights», en Peters A. (eds.), Studies in Global Animal Law. Beiträge zum ausländischen öffentlichen Recht und Völkerrecht (Veröffentlichungen des Max-Planck-Instituts für ausländisches öffentliches Recht und Völkerrecht), vol. 290, Springer, Berlin, 2020. https://doi.org/10.1007/978-3-662-60756-5_13.

${ }_{20}$ Riechmann, J., Un mundo vulnerable: Ensayos sobre ecología, ética y tecnociencia, Catarata, Madrid, 2000, p. 37.

${ }^{21}$ Hayward, T., «Anthropocentrism: A misunderstood Problem», Environmental Values 6, n. ${ }^{\circ}$ 1, p. 51 (traducción propia).

${ }^{22}$ Ferry, L., El Nuevo orden ecológico. El árbol, el animal y el hombre, Tusquets Editores, Barcelona, 1994, P. 61.

${ }^{23}$ Woods, K., «Environmental Human Rights», en R. Holifield, J., Chakraborty y G. Walker (eds.), The Routledge Handbook of Environmental Justice (pp. 149-159), Routledge, Abingdon, 2018, p. 151.

${ }_{24}$ Kant, I., Critica del juicio. Seguida de las observaciones sobre el sentimiento de lo bello y lo sublime (A. García Moreno \& J. Rubira, Trads.), Librería de Iravedra, Madrid, 1876 [1790], p. 124. 
consideración de los animales, el reino vegetal y el reino mineral como cosas a disposición del ser humano ${ }^{25}$. Así, al preguntarse Kant ¿para qué existe el reino mineral, vegetal y animal?, su respuesta es contundente: «Para el hombre, para los diversos usos que su inteligencia le muestra que debe hacer de todos estos seres ${ }^{26}$.

Sin embargo, a diferencia de Descartes, la superior jerarquía que otorga el planteamiento kantiano al ser humano en el reino de los fines no le lleva concluir un uso indiscriminado de aquel otro fin «inferior» conformado por lo orgánico, pues, para Kant, existen deberes para con la naturaleza que se derivan de la propia dignidad humana, es decir, plantea obligaciones humanas para con la naturaleza fundamentadas en su importancia para el cumplimiento de los fines humanos. En otras palabras, propone una protección indirecta/instrumental de tipo antropocéntrico, por la cual los deberes hacia los animales y otros seres nacen de los deberes para con la humanidad ${ }^{27}$.

La propuesta de Kant resulta coherente si tenemos en cuenta que dentro de las perspectivas procedimentales que siguen la tradición del contrato social las preguntas sobre quién formula los principios y para quién se formulan los principios tienen necesaria y estructuralmente la misma respuesta. Las partes que crean el contrato social formulan principios por los que esas mismas personas se comprometen a vivir juntas. En este marco, al considerar Kant que los animales carecen de conciencia propia ${ }^{28} \mathrm{y}$, por tanto, de la capacidad de reciprocidad moral, les niega de forma rotunda la posibilidad de que puedan tener dignidad o valor intrínseco. En este marco, tal como establece Nussbaum, los animales no pueden ser sujetos primarios de justicia porque no pueden formular contratos, haciendo que su valor sea solo derivado e instrumental ${ }^{29}$. Esto ubica al planteamiento kantiano como el precursor del «ambientalismo", el cual, si bien puede reconocer obligaciones respecto de la naturaleza, no asigna a esta el carácter de titular de derechos ${ }^{30}$.

Como se dijo, la propuesta kantiana ha sido trasladada al discurso de los derechos humanos a través del «derecho al ambiente sano», y este, si bien ha logrado importantes avances en materia de protección ambiental bajo la idea de que preservar aquellos recursos naturales necesarios para la supervivencia del hombre es un imperativo para la satisfacción de los bienes jurídicos protegidos por los instrumentos de derechos humanos, estos avances no se han ocupado de la inherente tensión entre su fundamento liberal-antropocéntrico y el cuidado de la naturaleza. De ahí que autores como Häberle consideren que si bien de la idea de protección del

${ }_{25} \mathrm{Al}$ respecto Kant, en su obra «Lecciones de ética», diría: «Aquello de lo que el hombre puede disponer han de ser cosas. A este respecto los animales son considerados como cosas». KANT, I., Lecciones de ética, Crítica, Barcelona, 1988 [1775-1781], pp. 191 y 192.

${ }^{26}$ Kant, I., op. cit, 1876 [1790], p. 119.

27 Kant, I., op. cit, 1988 [1775-1781], p. 290.

28 Idem nota 25.

29 Nussbaum, M., op. cit, 2007, p. 331.

30 Zaffaroni, E., op. cit, 2011, p. 69. 
ambiente puede llegarse a un antropocentrismo moderado, con ello no encontramos, todavía, un Kant «verde» ${ }^{31}$.

En efecto, tal como lo ha establecido Dobson, aunque el ambientalismo y el liberalismo pueden ser compatibles, no así el ecologismo y el liberalismo ${ }^{32}$. Para los liberales clásicos la facultad que se debe poseer para tener derecho a la consideración moral es la razón, para los liberales utilitaristas, como vimos, es la capacidad de sentir; sin embargo, el enfoque ecocéntrico va más allá, en este las facultades a tener en cuenta son la autorreproducción o la autorrenovación, lo que, como expone Dobson,

amplía la comunidad de «pacientes morales» más allá de lo que se encuentra incluso en Mill y Bentham, y proporciona pruebas circunstanciales de que, por mucho que lo intenten, los liberales no encontrarán mucho en su legado histórico para satisfacer a los ecocéntricos ${ }^{33}$.

Además, el «derecho al ambiente sano», como se dijo, sigue viendo al ambiente como un recurso que el ser humano tiene derecho a utilizar. Esto se enfrenta con la tesis de los «límites al crecimiento», para la cual los ecosistemas naturales tienen una capacidad de carga limitada, por lo que simplemente no pueden soportar todos los derechos que una humanidad en crecimiento podría reclamar ${ }^{34}$. Así, parece claro que el liberalismo antropocéntrico, por sí solo, carece de los recursos intelectuales para hacer frente a los problemas relacionados con los objetivos ambientales de los derechos humanos ${ }^{35}$.

Frente a esto y, por otro lado, el ecocentrismo mira a la crisis ambiental como una crisis ética, lo que significa que el mantener modelos de desarrollo insostenibles es un problema ético más que uno exclusivamente político o económico ${ }^{36}$. Propone un holismo moral, esto es, al todo, los ecosistemas, la biósfera, como sede de valor. Parte de la idea de que la tierra no es únicamente suelo, sino una fuente de energía que fluye a través de un circuito de suelos, plantas y animales que hacen posible la vida, en un proceso de interrelación continua entre los seres vivos y la materia inerte ${ }^{37}$. De aquello desprende una nueva ética que mira al oikós, a la casa grande $^{38}$, una ética de la tierra la cual, en palabras de Leopold, «ensancha las fron-

31 Häberle, P., El estado constitucional, Pontificia Universidad Católica del Perú, Lima, 2003, p. 116.

32 Dobson, A., Green Political Thought $4^{\text {th }}$ edition, Routledge, Abingdon, 2007, p. 50.

33 Dobson, A., op. cit, 2007, p. 155. Traducción propia.

${ }^{34}$ Hayward, T., Ecological Thought: An Introduction, Polity Press, Oxford, 1995, pp. 144-

145.

35 Dobson, A., op. cit, 2007, p. 155. Traducción propia.

36 Woods, K., Human Rights and Environmental Sustainability, Edward Elgar Publishing Limited, Cheltenham, 2010, p. 74.

${ }^{37}$ Leopold, A., Una ética de la tierra, Los Libros de la Catarata, Madrid, 2017, p. 193.

38 Sosa, N.M., Ética ecológica, Necesidad, posibilidad, justificación y debate, Libertarias/ Prodhufi, 1994, p. 121. 
teras de la comunidad para incluir suelos, agua, plantas y animales, o de manera colectiva, la tierra ${ }^{39}$.

El eje central del ecocentrismo se encuentra en el reconocimiento de la naturaleza como titular de derechos propios, con independencia del humano. Así, su traducción normativa son los derechos de la naturaleza. Estos exigen la preservación de los ciclos vitales de la naturaleza y la recuperación de ecosistemas dañados. Al respecto, es importante precisar que, desde el ecocentrismo, el ser humano se constituye como parte de ese todo llamado naturaleza, de ahí que los derechos de la naturaleza, a diferencia de los derechos de los animales, no puedan olvidar que las dinámicas ecológicas implican, también, relaciones de competencia y depredación en las que se incluye el humano. Por ello, tal como lo señaló Aldo Leopold, una ética de la tierra, por supuesto, no puede impedir la alteración, la gestión y el uso de los recursos naturales; "pero afirma su derecho a continuar existiendo y, al menos en algunos puntos, a continuar existiendo en estado natural $»^{40}$. Así, el ecocentrismo reconoce y defiende la necesidad de intervenir en el entorno para satisfacer nuestras «necesidades vitales», pues los valores propios del humano son una parte de ese amplio conjunto de valoraciones a considerar ${ }^{41}$. Estas características hacen que, en nuestra consideración, este enfoque también pueda encontrar una traducción en el discurso de los derechos humanos, pues no discute la existencia de intereses antropocéntricos, sino que los incorpora como parte de las relaciones que se dan en el mundo natural. Propone, entonces, una redefinición de lo humano, dando cuenta de la parte de nosotros que se constituye a partir de nuestra relación con la naturaleza y, por esta vía, una fundamentación posible de los derechos humanos de vocación ecocéntrica.

Con este marco, a continuación, presentaré cómo se ha desarrollado la visión antropocéntrica del derecho instrumental al medio ambiente sano dentro de la Corte IDH, dando cuenta de sus características y limitaciones. Precisado lo anterior, daré argumentos dirigidos a demostrar por qué la reciente categorización del mismo derecho como «autónomo» se diferencia de la protección antropocéntrica y se acerca a una visión ecocéntrica del ser humano.

39 Leopold da cuenta de cómo en un primer momento la ética se ocupó de la relación entre los individuos; en un segundo momento, de las relaciones de los individuos con la sociedad, y que, actualmente, es necesaria la transición hacia un tercer momento, la extensión de la ética a la naturaleza, es decir, a la relación del ser humano con la tierra, los animales y las plantas que crecen en ella. LeOpold, A., op. cit., 2017, pp. 181 y 182.

${ }^{40}$ LeOpold, op. cit., 2017, p. 182.

${ }^{41}$ Gudynas, E., «La senda biocéntrica: Valores intrínsecos, derechos de la naturaleza y justicia ecológica», Tabula Rasa: Revista de humanidades, núm. 13, 2010, pp. 45-71. 


\section{EL DERECHO AL MEDIO AMBIENTE SANO COMO DERECHO INSTRUMENTAL}

La multiplicidad de posiciones que se depositan dentro del derecho al medio ambiente ha provocado que dentro de la dogmática de los derechos resulte especialmente complejo determinar sus facultades y, por ende, su categorización; de ahí que autores como Alexy lo consideren un «derecho fundamental como un todo», pues, en sus palabras,

quien propone el establecimiento de un derecho fundamental al medio ambiente, o su adscripción interpretativa a las disposiciones de derecho fundamental existentes puede, por ejemplo, incluir en este conjunto o haz de posiciones, un derecho a que el estado omita determinadas intervenciones en el medio ambiente (derecho de defensa), un derecho a que el Estado proteja al titular del derecho fundamental frente a intervenciones de terceros que dañen el ambiente (derecho de protección), un derecho a que el Estado permita participar al titular del derecho en procedimientos relevantes para el medio ambiente (derecho al procedimiento) y un derecho a que el propio Estado emprenda medidas fácticas, tendientes a mejorar el ambiente (derecho a una prestación fáctica ${ }^{42}$.

Siguiendo la complejidad señalada, la fundamentación del derecho humano al medio ambiente resulta, también, de difícil categorización dentro del sistema interamericano. De esto da cuenta la Opinión Consultiva N. ${ }^{\circ}$ OC-23/17 de la Corte Interamericana de Derechos Humanos, de fecha 15 de noviembre de 2017, sobre medio ambiente y Derechos Humanos. En esta opinión se da respuesta, entre otras, a la consulta formulada por la República de Colombia sobre las obligaciones de los Estados en relación con el medio ambiente en el marco de la protección y garantía de los derechos a la vida y a la integridad personal. Se constituye, de esta forma, en un hito importante en la protección del medio ambiente en el campo del derecho internacional de los derechos humanos, pues, mediante ella, la Corte IDH desarrolla, por primera vez de manera extendida, la relación entre los derechos civiles y políticos y el contenido del derecho al medio ambiente sano consagrado de forma expresa en el artículo 11 del Protocolo de San Salvador.

Bajo este parámetro interpretativo la Corte IDH ha considerado la protección del medio ambiente como un elemento sine qua non para el disfrute de otros derechos humanos. Esta aproximación se enmarca en lo que varios autores -e inclusive la Corte IDH-denominan un enfoque instrumental de la protección del medio ambiente para la garantía de los derechos humanos y, en la vertiente inversa, un enfoque instrumental de los derechos humanos para la protección del medio ambiente. Así, la Corte ha clasificado los derechos especialmente vinculados al medio ambiente en dos grupos: I) los derechos cuyo disfrute es particularmente vulnerable a la degra-

${ }^{42}$ Alexy, R., Teoría de los derechos fundamentales, 2da ed., Centro de Estudios Políticos y Constitucionales, Madrid, 2007, p. 392. 
dación del medio ambiente, también identificados como derechos sustantivos, y II) los derechos cuyo ejercicio respalda una mejor formulación de políticas ambientales, también identificados como derechos de procedimiento. Estas dos formas de entender la protección del medio ambiente en el derecho internacional de los derechos humanos, ambas con un eje antropocéntrico, desarrollan el contenido principal de la opinión consultiva, el cual pasaré a detallar brevemente.

\subsection{El enfoque instrumental de la protección del medio ambiente para LA GARANTÍA DE LOS DERECHOS HUMANOS}

Desde el enfoque instrumental de la protección del medio ambiente para la garantía de los derechos humanos, la Corte IDH ha considerado que existe una relación de interdependencia e indivisibilidad entre los derechos humanos, el medio ambiente y el desarrollo sostenible, pues todos los derechos humanos son vulnerables a la degradación ambiental ${ }^{43}$. Sin embargo, ha indicado la Corte, existen derechos especialmente vulnerables a afectaciones ambientales, entre los que se encuentran los derechos a la vida, integridad personal, vida privada, salud, agua, alimentación, vivienda, participación en la vida cultural, propiedad, el derecho a no ser desplazado forzadamente y otros relacionados de forma indirecta como el derecho a la paz ${ }^{44}$. En particular, es especialmente fructífera la jurisprudencia de la Corte sobre protección ambiental en casos de derechos territoriales de pueblos indígenas. En estos casos la Corte IDH ha resaltado que la falta de acceso a los territorios y recursos naturales puede exponer a las comunidades indígenas a condiciones de vida de mayor vulnerabilidad ante enfermedades, además de ocasionarles sufrimiento y perjudicar la preservación de su forma de vida, costumbres e idioma ${ }^{45}$.

En esta línea, en la OC-23/17, la Corte detalla el contenido y alcance general de las obligaciones de respetar y garantizar los derechos a la vida y a la integridad personal en relación con afectaciones producidas por dańos al medio ambiente ${ }^{46}$. Así, en primer lugar, para garantizar las obligaciones de respeto que, en términos de Alexy, desarrollarían la vertiente de derecho de defensa del derecho a un medio ambiente sano, la Corte ha establecido que los Estados deben «abstenerse de contaminar ilícitamente el medio ambiente de forma que se afecte las condiciones que

43 Corte IDH, Opinión Consultiva OC-23/17, párrs. 54 y 63.

${ }^{44}$ Corte IDH, Opinión Consultiva OC-23/17, párr. 66.

45 Entre otros: caso Comunidad Indígena Yakye Axa vs. Paraguay. Fondo Reparaciones y Costas. Sentencia 17 de junio de 2005, párr. 137; caso Comunidad Indígena Sawhoyamaxa vs. Paraguay. Fondo, Reparaciones y Costas. Sentencia de 29 de marzo de 2006, párr. 118; caso del Pueblo Saramaka vs. Surinam. Excepciones Preliminares, Fondo, Reparaciones y Costas. Sentencia de 28 de noviembre de 2007, párrs. 121 y 122, y caso Pueblos Kaliña y Lokono vs. Surinam. Fondo, Reparaciones y Costas. Sentencia de 25 de noviembre de 2015, párr. 173.

46 Corte IDH, Opinión Consultiva OC-23/17, párr. 242. 
permiten la vida digna de las personas $»^{47}$. En segundo lugar, respecto de la obligación de garantizar, en la que, siguiendo la clasificación de Alexy, podríamos incluir las vertientes de derecho a la protección y a una prestación fáctica, la Corte ha considerado que los Estados deben adoptar todas las medidas apropiadas para proteger y preservar los derechos a la vida y a la integridad, debiendo prevenir, inclusive, que particulares vulneren dichos derechos. Así, especifica la Corte, «en el marco de la protección del medio ambiente, la responsabilidad internacional del Estado derivada de la conducta de terceros puede resultar de la falta de regulación, supervisión o fiscalización de las actividades de estos terceros que causen un dańo al medio ambiente» ${ }^{48}$.

Las obligaciones específicas que emanan de esta vertiente instrumental del derecho a un medio ambiente sano, conforme lo establece la Corte, son 1) actuar conforme al principio de prevención frente a daños ambientales significativos. Para el cumplimiento de esta obligación los Estados deben regular, supervisar y fiscalizar las actividades que puedan causar un daño significativo al medio ambiente; requerir y aprobar estudios de impacto ambiental; establecer un plan de contingencia para minimizar la posibilidad de grandes accidentes ambientales, y mitigar en casos de ocurrencia de daño ambiental ${ }^{49}$; 2) actuar conforme al principio de precaución cuando haya indicadores plausibles de que una actividad podría acarrear daños graves e irreversibles al medio ambiente, aun en ausencia de certeza científica, a efectos de la protección del derecho a la vida y a la integridad personal ${ }^{50}$, y 3 ) cooperar de buena fe con otros Estados para la protección contra daños al medio ambiente, notificando a estos cuando tengan conocimiento de que una actividad planificada bajo su jurisdicción podría generar un riesgo de daños significativos transfronterizos, así como consultando y negociando, de buena fe, con los Estados potencialmente afectados ${ }^{51}$.

\subsection{El ENFOQUE INSTRUMENTAL DE LOS DERECHOS HUMANOS PARA LA PROTECCIÓN DEL MEDIO AMBIENTE}

Desde un enfoque instrumental de los derechos humanos para la protección del medio ambiente, la Corte IDH ha establecido que existe un grupo de obligaciones que, en materia ambiental, se identifican como de procedimiento. Estas respaldan una mejor formulación de las políticas ambientales e integrarían la faceta de derecho al procedimiento del derecho al medio ambiente sano expuesta por Alexy. En este marco, la Corte detalla las obligaciones de los Estados sobre los derechos a 1) el acceso a la información; 2) la participación pública; y 3) el acceso a la justicia, en relación con las obligaciones estatales para la protección del medio ambiente.

47 Corte IDH, Opinión Consultiva OC-23/17, párr. 117.

${ }^{48}$ Corte IDH. Opinión Consultiva OC-23/17, párrs. 118-119.

${ }^{49}$ Corte IDH, Opinión Consultiva OC-23/17, párrs. 145-174.

${ }^{50}$ Corte IDH, Opinión Consultiva OC-23/17, párr. 180.

${ }^{51}$ Corte IDH, Opinión Consultiva OC-23/17, párr. 185. 
Sobre el acceso a la información, en su vertiente pasiva, es decir, sobre el derecho a recibir respuestas ante las solicitudes de información efectuadas, la Corte ha categorizado como de interés público las actividades y proyectos que podrían tener impacto ambiental ${ }^{52}$. Por esta razón, la información relativa a dichas actividades debe ser entregada sin necesidad de acreditar un interés directo para su obtención o una afectación personal ${ }^{53}$. Por otro lado, la garantía de este derecho incluye, además, la obligación positiva del Estado de suministrar, de oficio, información completa, comprensible, accesible y actualizada sobre la calidad ambiental, el impacto ambiental en la salud, los factores que lo influencian y sobre la legislación y las políticas relativas al medio ambiente ${ }^{54}$.

Sobre el derecho a la participación pública, la Corte ha establecido que los Estados tienen la obligación de garantizar la participación de las personas en la toma de decisiones y políticas que puedan afectar el medio ambiente. Este derecho debe ser garantizado desde las primeras etapas del proceso de toma de decisiones y puede realizarse siguiendo mecanismos tales como audiencias públicas; notificación y consultas; participación en procesos de formulación y aplicación de leyes, y mecanismos de revisión judicial55. En específico, sobre comunidades indígenas, la Corte ha establecido que se debe garantizar su derecho a la consulta y participación en todas las fases de planeación e implementación de un proyecto o medida que pueda afectar su territorio, de conformidad con sus costumbres y tradiciones ${ }^{56}$.

Finalmente, la Corte ha establecido que el derecho al acceso a la justicia permite al individuo velar por que se apliquen las normas ambientales y exigir que se repare cualquier violación a los derechos humanos causada por su incumplimiento. Así,

los Estados deben garantizar que los individuos tengan acceso a recursos, sustanciados de conformidad con las reglas del debido proceso legal, para impugnar cualquier norma, decisión, acto u omisión de las autoridades públicas que contraviene o puede contravenir las obligaciones de derecho ambiental; para asegurar la plena realización de los demás derechos de procedimiento, es decir, el derecho al acceso a la información y la participación pública, y para remediar cualquier violación de sus derechos, como consecuencia del incumplimiento de obligaciones de derecho ambiental ${ }^{57}$.

52 Caso Pueblo Indígena Kichwa de Sarayaku vs. Ecuador. Fondo, Reparaciones y Costas. Sentencia de 27 de junio de 2012, párr. 230; caso Claude Reyes y otros vs. Chile. Fondo, Reparaciones y Costas. Sentencia de 19 de septiembre de 2006, párr. 73.

${ }^{53}$ Caso Claude Reyes y otros vs. Chile, 2006, párr. 77 y caso Pueblos Kalińa y Lokono vs. Surinam. Fondo, Reparaciones y Costas. Sentencia de 25 de noviembre de 2015, párr. 261.

${ }^{54}$ Corte IDH, Opinión Consultiva OC-23/17, párrs. 213-225.

55 Corte IDH, Opinión Consultiva OC-23/17, párrs. 226-232.

56 Caso del Pueblo Saramaka vs. Surinam. Excepciones Preliminares, Fondo, Reparaciones y Costas. Sentencia de 28 de noviembre de 2007, párr. 133.

57 Corte IDH, Opinión Consultiva OC-23/17, párr. 237. 
Como se ve, los mecanismos que ha establecido la Corte para la protección del ambiente por medio del argumento de conexión son diversos y constituyen, sin duda, un importante avance en la materia. Sin embargo, el enfoque antropocéntrico kantiano al que responden hace que, en nuestra consideración, estos avances sean aún insuficientes. Bajo estos modelos el derecho al medio ambiente sano, ya sea en su vertiente individual o colectiva, sigue estando concebido en función de los intereses de las personas humanas.

Como lo expresó la Corte IDH en el párrafo 59 de la OC-23/17, en su dimensión individual, el derecho al medio ambiente sano constituye un elemento cuya vulneración puede tener repercusiones directas o indirectas sobre las personas. En esta faceta la protección de la naturaleza es relevante en tanto en cuanto su degradación afecte un bien jurídico de un ser humano. Del mismo modo, sobre su vertiente colectiva, la Corte sostiene que este derecho constituye un interés universal que se debe tanto a las generaciones presentes como a las futuras. Así, aunque no haya que observar deber alguno hacia la naturaleza considerada en sí misma, hay que tener en cuenta a las demás personas.

De esta postura, como se expuso anteriormente, nace la sostenibilidad como un complemento a la idea del desarrollo en favor de la continuidad exclusiva de la especie humana, ubicando al ser humano como el único sujeto de derechos. Ya hemos indicado en el apartado segundo los riesgos que para la naturaleza trae el fundamentar su protección, de forma exclusiva, en su utilidad para el ser humano. La consideración del ser humano como el fin último del reino de los fines -base de esta aproximación- hace que los argumentos que se pueden dar a favor de la afectación del ambiente, siguiendo objetivos antropocéntricos, sean infinitos. De ahí que, en nuestra consideración, una apuesta fuerte por la garantía de la naturaleza como un bien en sí mismo sea un complemento necesario, tal como parece dar cuenta la Corte IDH en la vertiente autónoma del derecho al medio ambiente sano, la cual pasaré a exponer a continuación.

\section{EL DERECHO AL MEDIO AMBIENTE SANO COMO DERECHO AUTÓNOMO}

Si bien los aportes de la OC-23/17 sobre el derecho a un medio ambiente sano se efectúan, principalmente, por su relación con los derechos a la vida e integridad física, en mi opinión, uno de los puntos que mayor impacto ofrecen es el reconocimiento expreso del derecho a un medio ambiente sano como un derecho autónomo en el sistema interamericano de protección de derechos. Este derecho, como ya se dijo, fue declarado como vulnerado, por primera vez en un caso contencioso, en la reciente sentencia del caso comunidades indígenas miembros de la Asociación Lhaka Honhat (nuestra tierra) vs. Argentina, de 6 de febrero de 2020. En el presente apartado me referiré al desarrollo jurisprudencial de este derecho tomando como base estas dos resoluciones de la Corte.

Así, en el párrafo 25 de la Opinión Consultiva, la Corte IDH establece que, dada la estrecha conexión entre la protección del medio ambiente con el desarrollo 
sostenible y los derechos humanos, actualmente diversos sistemas de protección de derechos humanos y, en particular, el Sistema Interamericano de Derechos Humanos reconocen el derecho al medio ambiente sano como un derecho en sí mismo. En el párrafo 62 desarrolla el contenido de este derecho declarando que, «a diferencia de otros derechos, este protege los componentes del medio ambiente tales como bosques, ríos, mares y otros como intereses jurídicos en sí mismos, aún en ausencia de certeza o evidencia sobre el riesgo a las personas individuales». Finalmente, precisa que el derecho al medio ambiente sano como derecho autónomo busca

proteger la naturaleza y el medio ambiente no solamente por su conexidad con una utilidad para el ser humano o por los efectos que su degradación podría causar en otros derechos de las personas, como la salud, la vida o la integridad personal, sino por su importancia para los demás organismos vivos con quienes se comparte el planeta, también merecedores de protección en sí mismos.

El contenido de este derecho ha sido, a su vez, ratificado en párrafo 203 de la sentencia del caso Lhaka Honhat vs. Argentina, con lo cual, la Corte parece reconocer un nuevo bien jurídico dentro del sistema interamericano, la naturaleza en sí misma. Siguiendo lo dicho por el profesor Simón Yarza, si el derecho a un medio ambiente sano consistiese únicamente en las condiciones necesarias para asegurar bienes fundamentales como la vida, la integridad física o la propiedad, la pretendida sustantividad propia del derecho desaparecería y su reconocimiento sería solo testimonial. Por ello, «un derecho al medio ambiente que no sea un mero corolario de otros derechos ya reconocidos habría de tener por objeto ora nuevos bienes jurídicos individuales, ora el medio ambiente como bien colectivo (la protección del entorno o de la naturaleza como tales) ${ }^{58}$. En este marco, el desarrollo del derecho al medio ambiente como derecho autónomo podría constituir un esfuerzo por sustantivar este derecho desde un enfoque ecocéntrico.

Si bien ni en la opinión consultiva ni en la sentencia del caso Lhaka Honnat se desarrollan las obligaciones específicas que nacen de este nuevo derecho autónomo, considero que tomando como referencia las puntualizaciones que se hacen respecto del mismo se pueden obtener ciertos rasgos que nos permiten dar cuenta de por qué esta construcción parece alejarse de la titularidad antropocéntrica individual o colectiva del derecho al medio ambiente.

Se podría creer, por ejemplo, que la consagración del derecho a un medio ambiente sano como un derecho autónomo es una respuesta a la dimensión humana colectiva de este derecho. La preservación de los componentes del medio ambiente podría ser un mecanismo para evitar un proceso de degradación ambiental que ponga en riesgo a toda la humanidad. Sin embargo, considero que la Corte IDH va un paso más allá al definir este derecho, pues, como reza en el antes citado párrafo 62 de la OC-23/17, lo que busca es proteger a la naturaleza y el medio ambiente no sola-

58 Simón Yarza, F., Medio ambiente y derechos fundamentales, Centro de Estudios Políticos y Constitucionales, Madrid, 2012, p. 64. 
mente por su conexidad con una utilidad para el ser humano o por los efectos que su degradación podría causar en otros derechos de las personas, sino por su importancia para los demás organismos vivos con quienes se comparte el planeta, también merecedores de protección en sí mismos. En este caso, a diferencia de la dimensión humana-colectiva de este derecho, la Corte pone el acento en la protección que ofrece para los demás organismos no humanos. Así, el objetivo no es ya conservar la humanidad, sino a todos los organismos que conviven con ella.

Esta particularidad ubica al desarrollo jurisprudencial efectuado por la Corte IDH más cercano a las reivindicaciones del modelo ecocéntrico de acuerdo con el cual la naturaleza posee fines y valores en sí misma, pudiéndose predicar una dignidad de ella. La definición que da la Corte sobre la vertiente autónoma de este derecho reconoce que existen algunos perjuicios ambientales que no solamente afectan a los seres humanos, sino, también, a otros habitantes del planeta. En este contexto, parece que la Corte ha buscado dar un paso más, comprendiendo que, como lo expresa el juez Zaffaroni, la naturaleza, el planeta, la Tierra, la Pachamama, es otro ente con el que podemos dialogar y, más aún, con el que debemos dialogar ${ }^{59}$.

Esta precisión nos permite identificar, también, las distancias entre el desarrollo jurisprudencial de la Corte IDH, que en nuestra opinión deriva de la incorporación del enfoque ecocéntrico, de otras posturas como la del enfoque de las capacidades de Nussbaum. Como se expuso anteriormente, Nussbaum limita el reconocimiento de derechos para aquellas especies sensibles, pues solo de estas se puede identificar el dolor causado por el ser humano como una barrera para el libre desarrollo de sus capacidades naturales. Por el contrario, una postura ecocéntrica, como la que propone la ética Pachamama, reconoce la titularidad de derechos no solo para entes sensibles, sino para todo el entorno, incluidos entes que podríamos llamar inertes. De esta forma, la ética de la Pachamama, como le expresa Zaffaroni,

busca reconocer que debemos actuar respetando a otros seres con derechos y cuyo reconocimiento es condición de nuestra propia supervivencia como especie interdependiente de otras y de otros entes terrenos en su existencia, es un fortalecimiento de la capacidad de escucharnos entre nosotros y de escuchar lo que nos dicen todos los demás entes del planeta ${ }^{60}$.

Considero relevante la referencia al trabajo académico del juez Eugenio Zaffaroni, pues da cuenta de que en el debate llevado en el seno de la Corte IDH existía plena conciencia de los efectos del reconocimiento del derecho a un medio ambiente sano como derecho autónomo. Esto parece claro al examinar los votos particulares del juez Humberto Sierra Porto tanto en la OC 23/17 como en el caso Lhaka Honhat vs. Argentina, en los cuales da a conocer su discrepancia, justamente, respecto de la decisión de la mayoría en este punto. Parece entonces que la Corte se aleja de los esquemas filosóficos occidentales y se nutre de la cosmovisión de los pueblos indí-

59 Zaffaroni, op. cit., 2011, p. 125.

60 Zaffaroni, op. cit., 2011, p. 134. 
genas de la América Andina para fundamentar un nuevo derecho que revoluciona la idea de dignidad humana incorporando una comprensión holística de su concepto.

La pregunta es entonces ¿cuál es el contenido del derecho al medio ambiente derivado de un enfoque ecocéntrico? y ¿se podrían trasladar las garantías de procedimiento dadas a la versión antropocéntrica de este derecho a este nuevo enfoque ecocéntrico? Al respecto resulta interesante revisar el debate doctrinal citado por Navarro Mendizábal. Para un sector de la doctrina, si no es posible proteger el derecho a un medio ambiente abstracto y mal definido, se puede muy bien dar el derecho a cada uno de actuar cuando su medio ambiente es objeto de discusión, mediante los derechos de información, participación y tutela judicial. El contenido del derecho al medio ambiente así planteado es ante todo procedimental y no sustantivo. Por otro lado, otro sector de la doctrina, en el que destaca Loperena Rota, presenta como un absurdo que nos conformemos con que se nos reconozcan a los ciudadanos dichos derechos de participación, esto implicaría no respetar las reglas de lógica jurídica negando la sustantividad de un derecho y proponiendo su tutela. Si no hay derecho sustantivo, ¿a qué se orienta la participación o la tutela judicial? Como lo menciona Navarro, desde una perspectiva teórica, cabe reconocer un derecho y no disponer de un sistema adecuado de protección, pero nunca al revés $^{61}$. En línea con la segunda postura, considero que la garantía de un derecho al medio ambiente sano como derecho autónomo derivado de un enfoque ecocéntrico exige la elaboración de un contenido sustancial del mismo. En dicha tarea, el concepto desarrollado por la Corte Interamericana de daño ambiental significativo nos puede arrojar algunas luces.

En el párrafo 120 de la OC-23/17 la Corte IDH establece que para que surjan obligaciones positivas hacia el Estado debe existir una relación de causalidad entre la afectación a la vida o a la integridad y el dańo significativo causado al medio ambiente. Conforme lo expone la Corte IDH, cualquier daño al medio ambiente que pueda conllevar una violación de los derechos a la vida o a la integridad personal debe ser considerado como un daño significativo. La existencia de un daño significativo en estos términos es algo que deberá determinarse en cada caso concreto, con atención a las circunstancias particulares del mismo. Esto quiere decir que las obligaciones deben cumplirse bajo un estándar de debida diligencia, el cual debe ser el apropiado y proporcional al grado de riesgo de dańo ambiental. De esta forma, las medidas que un Estado deba adoptar para la conservación de ecosistemas frágiles serán mayores y distintas a las que corresponda adoptar frente al riesgo de daño ambiental de otros componentes del medio ambiente y estas pueden variar con el tiempo, por ejemplo, con base en descubrimientos científicos o nuevas tecnologías ${ }^{62}$.

${ }^{61}$ Navarro Mendizábal, I., «El derecho a un medio ambiente adecuado, ¿̨es un derecho?», en Desafios actuales a los derechos humanos: el derecho al medio ambiente y sus implicaciones, Debates del Instituto Bartolomé de las Casas (pp. 64-91), Dykinson, Madrid, 2009, pp. 79-80.

${ }^{62}$ Corte IDH, Opinión Consultiva OC-23/17, párr. 140. 
Esta idea del daño significativo ambiental desarrollada como núcleo sustantivo de la versión antropocéntrica del derecho al medio ambiente sano, en mi opinión, podría ser trasladada a la protección de la naturaleza como un bien jurídico en sí mismo. Se afectaría entonces el contenido sustancial de este derecho cuando la intervención humana amenace con obstruir los ciclos vitales de la naturaleza, cuando impida la continuación de los procesos de cooperación existentes entre los organismos que conforman el entorno. Este daño responderá también a la evolución de la ciencia. El desarrollo de la tecnología verde podría hacer que una intervención humana sobre el entorno natural que actualmente se pueda considerar dańina para sus ciclos vitales posteriormente no lo sea. Se crearía, además, un núcleo esencial de protección para ecosistemas frágiles, ya no en razón de su funcionalidad para el ser humano, sino porque en estos entornos cualquier tipo de intervención puede significar una alteración de sus procesos naturales.

Me parece también relevante referir un aspecto de la teoría de Nussbaum que, salvando la ya mencionada distancia que tiene esta con el ecocentrismo, puede complementar la identificación del daño significativo a la naturaleza. Para esta autora, los seres humanos no deben fiarse demasiado de suposiciones indirectas sobre las capacidades animales; por el contrario, deben tratar de observar qué es lo que cada criatura considera importante basándose en lo que esta hace. Así, para Nussbaum, parte del respeto por otras especies se manifiesta a través de la disposición a observar y estudiar aprendiendo los ritmos internos de una comunidad animal y la noción de valor que su modo de vida expresa ${ }^{63}$. Este desarrollo puede ser trasladado también a la protección más amplia que provee el ecocentrismo aplicando la observación ya no solo con los seres sensibles, sino con toda la naturaleza. Dicha observación permitirá un diálogo respetuoso entre especies sobre el cual construir la armonía que protege la Pachamama.

Esta concepción implica, por tanto, cambios sustanciales en la idea de dignidad humana y, por esta vía, de los sujetos capaces de activar el sistema interamericano de derechos humanos como víctimas. En la Opinión Consultiva N. ${ }^{\circ}$ OC-22/16, del 26 de febrero de 2016, sobre titularidad de derechos de las personas jurídicas en el sistema interamericano, la Corte Interamericana estableció que conforme al artículo 1.2 de la Convención los derechos reconocidos en dicho instrumento corresponden a únicamente a personas, es decir, a seres humanos. Lo anterior implica que en el marco de la Convención Americana las personas jurídicas no son titulares de los derechos establecidos en esta y, por tanto, no pueden presentar peticiones o acceder directamente, en calidad de presuntas víctimas.

A este criterio respondió la Comisión Interamericana de Derechos Humanos en el año 2004 al declarar inadmisible la petición presentada por un ciudadano panameño respecto del Parque Natural Metropolitano en Panamá, dado que la petición no individualizaba víctimas concretas y era excesivamente amplia. El peticionario alegaba que el Gobierno había violado el derecho a la propiedad de todos los

${ }^{63}$ Nussbaum, op. cit., 2007, p. 366 
ciudadanos panameños al permitir la construcción de un proyecto vial que atravesaba una reserva natural protegida. Después de ocho años, la Comisión determinó que, en vista de que no se habían identificado víctimas humanas específicas, la petición era inadmisible ${ }^{64}$.

La consagración del derecho a un medio ambiente sano como derecho autónomo promete cambiar esta jurisprudencia, pues al identificar a los bosques, ríos, mares y otros como intereses jurídicos en sí mismos, aun en ausencia de certeza o evidencia sobre el riesgo a las personas individuales, se crea un nuevo sujeto de protección de tipo abstracto en el marco del sistema interamericano. Esto significa abrir paso para que la naturaleza pueda ser considerada víctima, cambiando sustancialmente la jurisprudencia en esta materia. Al respecto, se pronuncia también el juez Zaffaroni en su libro La Pachamama y el humano, indicando que la mera circunstancia de que cualquiera puede accionar en defensa de la naturaleza, sin que sea menester invocar $-y$ menos probar- la condición de damnificado, provocará que diferentes personas, según sus simpatías con los entes naturales no humanos, ejerzan acciones en su defensa ${ }^{65}$.

Por último, el reconocimiento de la naturaleza como víctima para el sistema interamericano le otorga también la posible condición de tercero agredido. Esto, como lo manifiesta Zaffaroni, hace que sean lícitos en defensa de la naturaleza actos como las sentadas, colocación de obstáculos al avance de maquinarias de desmonte y otros medios de lucha no violenta ${ }^{66}$.

\section{CONCLUSIONES}

El cambio al paradigma ecocéntrico al que parece inclinarse la Corte Interamericana de Derechos Humanos, sin duda, representa un desafío hacia la construcción de una nueva epistemología difícilmente explicable dentro de las construcciones dogmáticas efectuadas a partir del enfoque antropocéntrico. Esta pone en cuestión la conceptualización misma de los derechos humanos como aquellos que se poseen por el hecho de ser persona; de ahí que, como lo expresa Zaffaroni, requiera de una nueva jurisprudencia, cuyas consecuencias prácticas son de momento difíciles de prever, pero lo cierto es que no responderá a los criterios que hasta el presente se vienen manejando ${ }^{67}$.

En mi opinión, lo anterior no constituye un debilitamiento del poder emancipador de la idea de los derechos humanos; por el contrario, abre las puertas hacia una interpretación holística capaz de nutrirse no solo de los postulados clásicos, sino,

${ }^{64}$ Shelton, D., «Derechos ambientales y obligaciones en el sistema interamericano de derechos humanos", en Anuario de Derechos Humanos de la Universidad de Chile, número 6 (pp. 111127), 2010, p. 126.

${ }_{65}$ ZafFaroni, op. cit., 2011, p. 141

${ }^{66}$ ZafFaroni, op. cit., 2011, p. 142

67 Zaffaroni, op. cit., 2011, p. 144 
además, de aquellas otras cosmovisiones históricamente relegadas dentro del debate doctrinal, tales como las provenientes de los pueblos de la América Andina y en particular de la ética de la Pachamama. De esta forma se podrá otorgar un mayor grado de protección a la naturaleza, a aquello que es inherente al ser humano no como su piloto sino como un pasajero más. Como lo expresa Boaventura de Sousa, la evolución del derecho en los últimos 50-60 años ha demostrado que el mejor mecanismo jurídico para garantizar la eficacia de los derechos es la existencia de garantías que den forma real a esos derechos; en el caso de la naturaleza esa dignidad y esa sobrevivencia solo se puede garantizar efectivamente dándole titularidad de derechos ${ }^{68}$.

ReCiBIDO: septiembre de 2020; ACEPTADO: diciembre de 2020

${ }^{68}$ De Sousa Santos, B., Derecho y emancipación, Centro de Estudios y Difusión del Derecho Constitucional-Corte Constitucional de Ecuador, Quito, 2012, p. 23. 
